\title{
A study on the relationship between energy performance and IEQ parameters in school buildings
}

\author{
Blanka Cabovská ${ }^{*}$, Despoina Teli ${ }^{1}$, Jan-Olof Dalenbäck ${ }^{1}$, Sarka Langer $^{1,2}$ and Lars Ekberg ${ }^{1,3}$ \\ ${ }^{1}$ Chalmers University of Technology, Division of Building Services Engineering, Department of Architecture and Civil \\ Engineering, SE-412 96, Göteborg, Sweden \\ ${ }^{2}$ IVL Swedish Environmental Research Institute, P.O.Box 53021, SE-40014 Göteborg, Sweden \\ ${ }^{3}$ CIT Energy Management AB, SE-41288 Göteborg, Sweden
}

\begin{abstract}
Over the last decades, strong focus has been placed on the energy efficiency of buildings; not least school buildings. Energy performance (EP) of buildings is nowadays in principle described by one single indicator based on purchased energy in $\mathrm{kWh} / \mathrm{year} \cdot \mathrm{m}^{2}$. Another important building performance aspect is the indoor environmental quality. This study's overarching goal is to identify school buildings with a good balance between energy performance and indoor environment. Thus, this paper investigates possible correlations between information given in energy performance certificates (EPCs/e.g. energy use, year of construction, type of ventilation) and measured indoor environmental parameters. The work comprises investigation of approximately 20 school buildings with different ventilation systems in Gothenburg. In-situ investigations of the buildings' properties and ventilation systems were conducted. Indoor environmental parameters were recorded during one week in each classroom. In this paper, indoor temperature, absolute humidity added indoors and $\mathrm{CO}_{2}$ concentration data are compared with the corresponding school's energy performance data and ventilation type. Results suggest that mechanically ventilated buildings have clearer relationships between energy performance, building indicators and measured indoor environment. For buildings such as naturally ventilated, the relationships are usually weak, and the values spread over much wider ranges.
\end{abstract}

\section{Introduction}

Studies have confirmed the importance of highquality indoor environment and its impact on health, performance or absenteeism [1]. In school buildings, this is of a particular importance, as schools accommodate more sensitive occupants for a substantial part of their day. However, recent years have been characterized by an increased focus on improving energy efficiency of buildings. In many cases, measures to reduce the energy use of a building affect the indoor environmental quality (IEQ). These effects may be positive, in terms of improved thermal comfort (TC) conditions [2], or negative, resulting in poor indoor air quality (IAQ) [3].

When attempting to improve a building's energy performance in design, it is crucial to consider any potential impacts on IEQ. In many cases, additional actions must be taken to fulfil the required levels of IEQ, too. Some of these additional measures can affect the energy consumption of the building. One example is the need for installation of a mechanical ventilation system. Such a system can improve IAQ and thermal comfort but requires additional energy for its operation. Therefore, it is important to understand mutual relations between energy use and IEQ and to analyse the benefits of design solutions and potential drawbacks.

To assess energy performance and to allow for a straightforward comparison between buildings, the energy performance certificate (EPC) was first introduced by EPBD in 2002 [4]. EPC can serve as an important instrument to promote energy efficiency in buildings, but it can also be used as a powerful tool when analysing the building stock [58]. Nowadays, energy performance of buildings in Sweden is described by one single indicator based on purchased energy and weighting factors. This indicator is based on actual measured energy during a period of one year. Weighting factors are used to normalize the value with respect to weather and primary energy. No such overall evaluation method exists for the indoor environment, although it is equally - if not more - important. Therefore, any links between energy performance and the overall indoor environmental quality are to a large extent unknown.

\footnotetext{
* Corresponding author: blanka.cabovska@chalmers.se
} 
Apart from the energy performance, additional information can be found in the Swedish version of EPC, such as year of construction, heated floor area and measures recommended to improve energy efficiency. All these data can serve as important inputs for analysis.

The aim of the project "Energy performance and indoor environmental quality in school buildings" is to study relationships between energy performance and IEQ, with focus on IAQ, and identify school buildings which excel in both these areas. This paper presents results from an initial analysis of buildings' energy performance data from EPCs and IEQ values collected during measurement campaigns conducted in primary schools in Gothenburg. The aim is to answer the question on whether a building's energy performance based on accessible information from EPCs could provide an indication of the quality of the IEQ.

\section{Methods}

\subsection{Description of the sample}

Initially, 30 schools were selected in cooperation with the municipal property manager Lokalförvaltningen in Gothenburg so that the sample represents the typical school building stock in the city. The selected buildings cover a wide range of construction years, building materials and ventilation systems. Figure 1 illustrates energy performance values and years of construction of school buildings in Gothenburg.

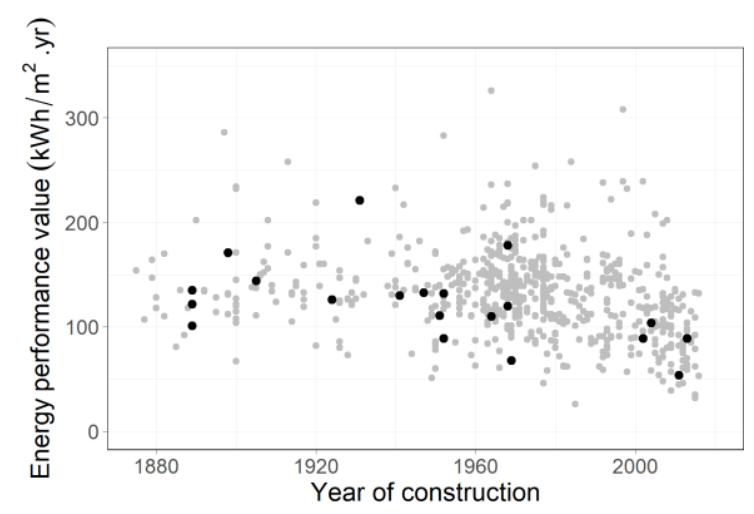

Figure 1. Energy performance value against year of construction of school buildings in Gothenburg. Black dots represent the school buildings selected for this analysis.

The buildings were grouped according to their main ventilation system into three categories. For description of the ventilation categories, see Table 1.
Table 1. Ventilation categories of the investigated schools

\begin{tabular}{|c|c|}
\hline Ventilation category & $\begin{array}{c}\text { Description of } \\
\text { ventilation system type }\end{array}$ \\
\hline Category A & $\begin{array}{c}\text { Supply of untreated air - } \\
\text { natural ventilation, } \\
\text { extract ventilation }\end{array}$ \\
\hline Category B & $\begin{array}{c}\text { Mechanical supply and } \\
\text { exhaust with constant air } \\
\text { flow (CAV) }\end{array}$ \\
\hline Category C & $\begin{array}{c}\text { Mechanical supply and } \\
\text { exhaust with variable air } \\
\text { flow (VAV) or demand- } \\
\text { control ventilation (DCV) }\end{array}$ \\
\hline
\end{tabular}

Most buildings are used solely as school buildings, without areas devoted to different purposes. One exception is a school, where, according to information in its EPC, $14 \%$ of the floor area is used as swimming pool.

Most school buildings in the sample are connected to the district heating network for heating and hot water. One of the buildings uses an electrical heat pump and one uses oil boiler for heating and hot water.

Some of the buildings had to be excluded from this analysis due to the lack of all required data, such as EPCs, and lack of access due to corona restrictions. A total of 21 school buildings are included in the final analysis with two investigated classrooms per building.

\subsection{Description of data collection and processing}

The measurements were performed during the heating seasons of 2019 and 2020 and were finished by March 2020. In each school building, the measurement campaign took 5 days (Monday morning to Friday afternoon), except from a few buildings, where it was not possible to start measurements early morning, so the measurements started on Monday afternoon.

Air temperature, relative humidity $(\mathrm{RH})$ and $\mathrm{CO}_{2}$ concentrations were measured using dataloggers Wöhler CDL 210 with two-minute intervals. Operative temperature was measured in 5-minute intervals with TinyTag TK 4023 temperature sensors placed a in small sphere (ping-pong ball). More detailed description of measurement data collection can be found in [9]. From the measurements, different metrics were extracted for analysis, i.e. weekly average, weekly average during occupied hours and $95^{\text {th }}$ percentile for the $\mathrm{CO}_{2}$ concentration. In this analysis, weekly average values are used, however in many cases also other metrics were investigated.

In addition to measurements, the latest valid Energy Performance Certificates (EPC) of the schools were collected. Only those buildings where 
all data were available were used for further analysis.

Due to recent legislative changes, a primary energy indicator is now used for the evaluation of energy performance in the latest version of EPCs. However, this change was introduced in 2019 and the newest version of EPC have been issued for only a small fraction of the buildings so far. For most of the buildings, only older versions of EPCs are currently available, where primary energy is not considered. As a basis for the energy performance value (Energiprestanda), the Energi-Index is calculated in all versions of EPCs. This number is a normalized sum of energy use for space heating, comfort cooling, hot water and other energy for building operation, i.e. all energy except for that directly used by the tenant. The Energi-Index is then divided by heated floor area to obtain the specific energy performance value $\left(\mathrm{kWh} /\right.$ year per $\mathrm{m}^{2}$ floor area), which was used in this analysis. This value was presented in the older versions of the certificate as the main energy performance indicator.

In addition to the specific energy performance value as described above, the electricity for the operation of the building itself (Fastighetsel) was also used in the analysis. This value includes electricity for the operation of ventilation systems, pumps, elevators, outdoor lighting etc. This value was also normalized with respect to the floor area (kWh/year per $\mathrm{m}^{2}$ floor).

Some additional data were collected during the building selection process and building inspections, such as information about main ventilation system used in the building, especially in the investigated classrooms. Even though EPC contains some information about ventilation systems, it does not state the main system in the building. Therefore, this information was collected and verified separately.

\section{Results}

\subsection{Energy performance and building characteristics}

This part of the analysis investigates potential relationship between building characteristics available in the EPC and the energy performance values of all 21 school buildings studied.

\subsubsection{Year of construction, energy performance and electricity for building operation}

Figure 2 shows the relationship between year of construction and energy performance value of the investigated buildings, grouped by ventilation type (A, B, C, see Table 1). A slight negative tendency between year of construction and energy performance value can be observed, which corresponds to the increasing demands on energy efficiency of newly constructed buildings. Pearson's correlation coefficient, $r$, is equal to $-0,42$ ( $p$-value $<0,01)$, which indicates moderate and significant correlation.

The building with the lowest energy performance value is equipped with a heat pump for heating and hot water. The building with the second lowest energy performance value has been recently extended with a new part. The measurements were conducted in the new part which has its own EPC. However, the EPC uses as a year of construction the year when the original object was constructed. This is an illustration of the special caution required when analysing EPC data.

When focusing on the ventilation system types, it can be observed that most of the older buildings are equipped with systems belonging to ventilation category A (natural or extract ventilation only). The younger the buildings are, the more advanced systems are used. The figure also shows that some of the older school buildings have already been equipped with mechanical supply and exhaust systems (category B). This can also indicate that renovation has been conducted. Unfortunately, EPCs do not usually include information about building renovation year or its scope. Therefore, year of construction as an indicator should be used carefully in further analysis, if no other additional information about the building is available.

Patterns in Figure 2 suggest that there are differences among ventilation groups. A relationship can be observed for category B $(r=-0,42$, $p$-value $0,14)$ and especially $C(r=-0,64, p$-value 0,01$)$. No relationship can be identified for buildings in ventilation category A $(r<0,01, \mathrm{p}$-value 0,98$)$. However, the latter could be due to the lack of cat A schools built post-1950s.

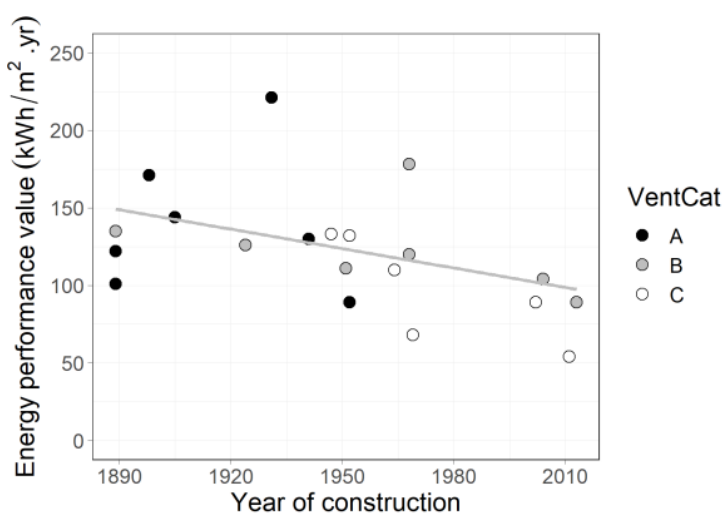

Figure 2. Energy performance value against year of construction of the buildings. Regression line is added for the whole sample. VentCat: Ventilation category. 


\subsubsection{Year of construction and electricity for building operation}

Electricity for building operation represents the operational part of the energy performance and makes it possible to study how this part has developed in comparison to the total energy performance.

Figure 3 shows the relationship between year of construction and electricity for operation of the building. Buildings being built more recently seem to use more electricity $(\mathrm{r}=0,42, \mathrm{p}$-value $<0,01)$. However, for the oldest buildings, the range of this value is very wide, from values under 5 $\mathrm{kWh} / \mathrm{m}^{2}$.year to values reaching $30 \mathrm{kWh} / \mathrm{m}^{2}$.year. Interestingly, most of the oldest buildings with the widest electricity range belong to ventilation category A. For ventilation category B, strong and significant correlation was observed $(r=0,86$, $p$ value $<0,01)$. For the other two categories, the correlation is weak and insignificant.

To investigate this relationship in more detail, it would be necessary to see measured values for each of the systems included in the electricity value separately (such as ventilation system). However, this data is not usually available.

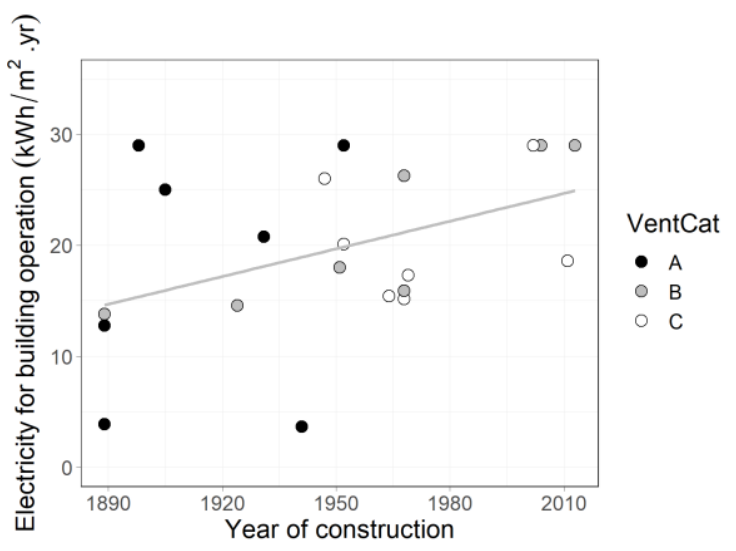

Figure 3. Electricity for building operation against year of construction of the buildings. Regression line is added for the whole sample.

As electricity for building operation includes electricity for ventilation systems in the building, it is interesting to compare the electricity for building operation among ventilation categories. Figure 4 illustrates box plots of electricity for building operation by ventilation category. The highest deviation of the values can be observed in category A, which was also seen in Figure 3. Categories B and $\mathrm{C}$ have more similar range of values, but never drop under $14 \mathrm{kWh} / \mathrm{m}^{2}$.year. In category $\mathrm{A}$, there are several buildings with lower values. Median values in all categories are very similar, with category A having the highest value.

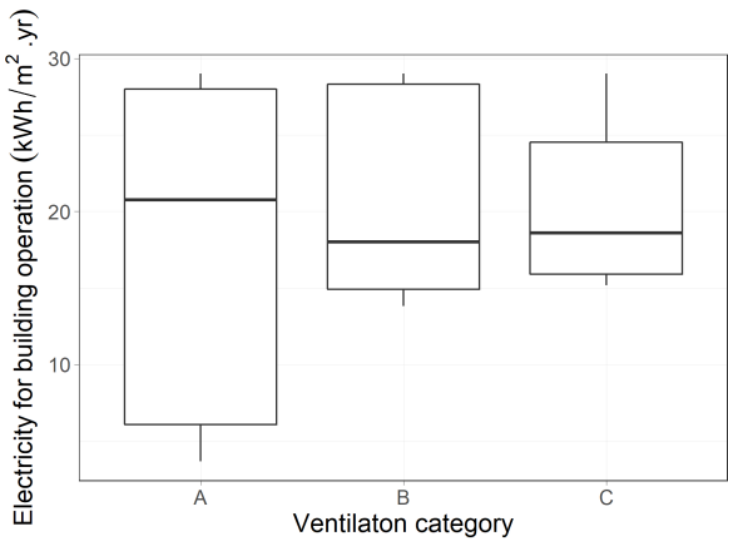

Figure 4. Boxplots of electricity for building operation for different ventilation categories.

\subsection{Energy performance and measured indoor environmental parameters}

As the measurements were performed usually in two classrooms in each building, the main unit of this part of analysis is a classroom. Total number of classrooms is 42 .

\subsubsection{Operative temperature and energy performance}

The relationship between the energy performance value and the weekly average operative temperature is illustrated in Figure 5. The Pearson's correlation coefficient calculated for the whole sample is equal to $r=-0,30$ with a $p$-value of 0,06 , which indicates a relatively weak and insignificant relationship.

However, when considering the relationship by ventilation categories, there is a strong negative and significant correlation for categories $\mathrm{B}$ and $\mathrm{C}(\mathrm{r}=$ 0,72 and $-0,77$, respectively; $p$-value $<0,01$ for both categories). In case of category $\mathrm{A}$, the relationship is positive, but weak and insignificant $(r=0,18, p$-value $0,54)$.

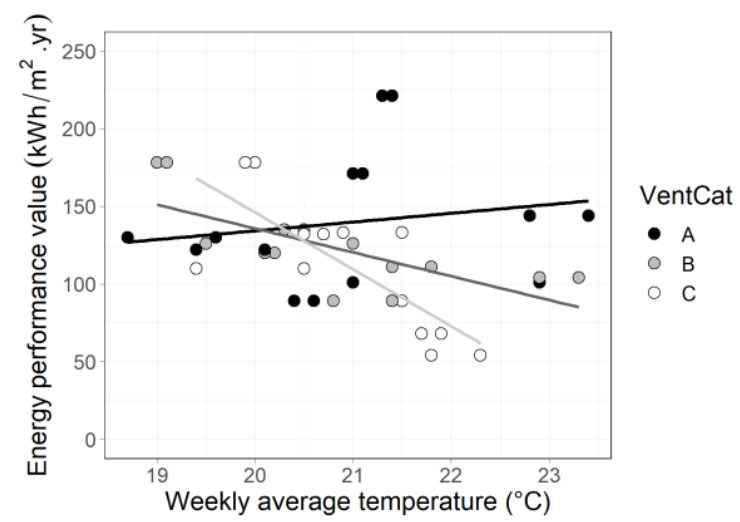

Figure 5. Energy performance values against weekly average temperature in the classrooms. Regression lines 
are added in corresponding shades for each ventilation category.

\subsubsection{Humidity added indoors and energy performance}

Figure 6 illustrates the relationship between energy performance value and added absolute humidity value $\left(\mathrm{g} / \mathrm{m}^{3}\right)$. The added humidity values were calculated as a difference between absolute humidity outdoors and indoors. Weekly average values were used for calculations. Corresponding outdoor weather conditions were obtained from the Gothenburg's local environmental administration through its ambient air monitoring program.

Figure 6 shows quite a random pattern and there does not seem to be a clear relationship. The Pearson's correlation coefficient is equal to 0,21 with p-value 0,17 , which confirms that there is weak and not significant correlation between these two variables.

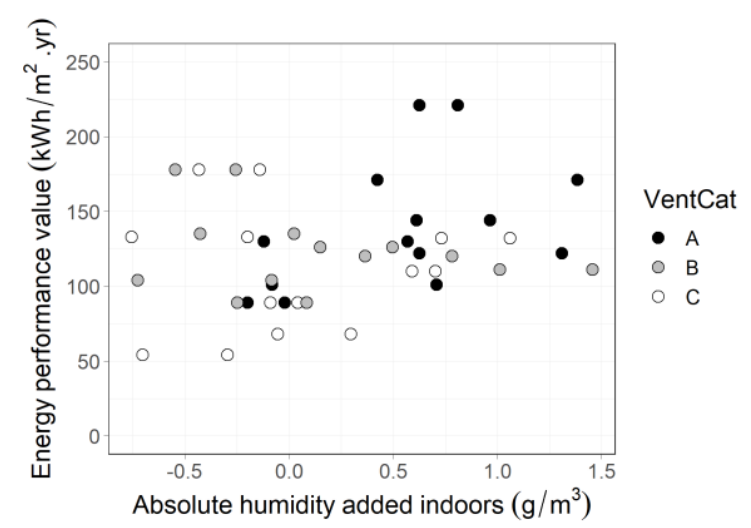

Figure 6. Energy performance value against weekly average added humidity in the classrooms.

When considering individual ventilation categories, correlation coefficients show some tendencies in individual categories, more specifically in category A, however the relationship is not significant ( $p$-value $>0,05)$. Very similar results can be observed when considering added humidity values only during occupied hours.

\subsection{3 $\mathrm{CO}_{2}$ concentration and energy performance}

Figure 7 depicts relationship between average $\mathrm{CO}_{2}$ concentrations during the whole week and energy performance values. The figure clearly illustrates differences between ventilation category $\mathrm{A}$ and categories $\mathrm{B}$ and $\mathrm{C}$ when considering the average $\mathrm{CO}_{2}$ concentration levels.

Pearson's correlation coefficient for the whole sample equals $r=0,24$ with $p$ value 0,13 . This indicates quite weak and insignificant relationship between the investigated variables.
If we distinguish among ventilation categories, the correlation coefficient for category A equals $r=0,06$ ( $p$ value $=0,83$ ), for category $B r=-0,41$ $(p=0,14)$ and for category $\mathrm{Cr}=0,04(\mathrm{p}=0,89)$. These values indicate weak and insignificant correlations. Using $\mathrm{CO}_{2}$ concentration during occupied hours as well as using 95-percentile values showed very similar results.

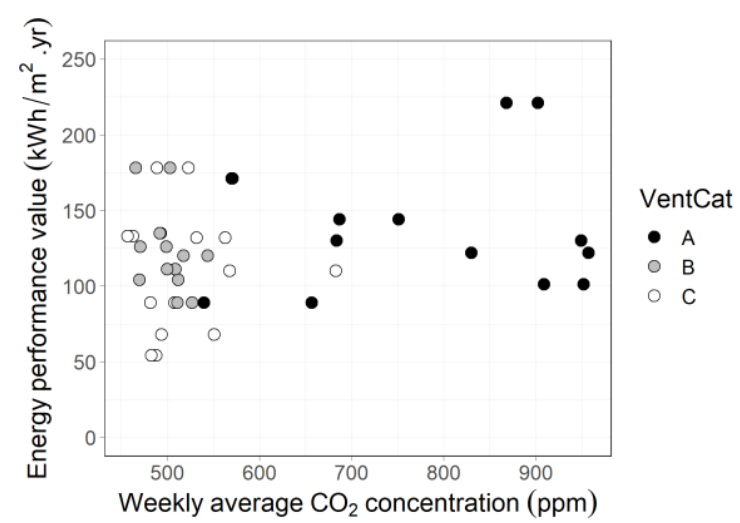

Figure 7. Energy performance value against weekly average $\mathrm{CO}_{2}$ concentration in the classrooms.

As can be seen in Figure 7, most of the classrooms equipped with systems of category A tend to have higher $\mathrm{CO}_{2}$ concentration compared to the other two categories, as would be expected for the cold season. This tendency can be confirmed when investigating Figure 8. Buildings equipped with ventilation system categories $\mathrm{B}$ and $\mathrm{C}$ show lower average $\mathrm{CO}_{2}$ concentrations during occupied hours and the concentrations do not differ significantly between various buildings. In all cases, the average concentration did not exceed $1000 \mathrm{ppm}$. However, buildings equipped with ventilation system category A show much higher deviation in average $\mathrm{CO}_{2}$ concentration and much higher average value among all the buildings, compared to the other two ventilation system types. Pairwise Wilcoxon rank sum test has confirmed significant differences ( $p$-value $<0,01$ ) between groups $\mathrm{A}-\mathrm{B}$ and $\mathrm{A}-\mathrm{C}$. 


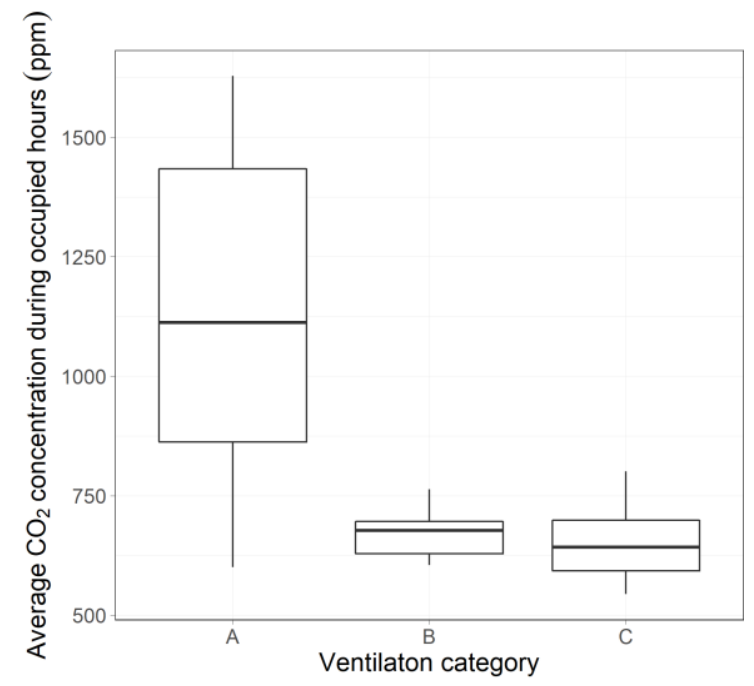

Figure 8. Boxplots of average $\mathrm{CO}_{2}$ concentration during occupied hours for different ventilation categories.

The same differences between pairs of ventilation groups can be observed when average concentrations during the whole measurement week are considered. It is also interesting to note that in spite of the expectation that natural ventilation will perform the worst, there are classrooms having average $\mathrm{CO}_{2}$ concentration below the typically recommended limit of 1000 ppm (500 ppm above outdoor concentration, [10]) .

\section{Discussion}

\subsection{Analysis of energy performance, building indicators and measured values}

In the first part of the analysis, the focus was on building performance indicators. An expected tendency of negative relationship between year of construction and energy performance value was observed. When focusing on ventilation categories, correlation is higher for mechanically ventilated buildings (category $\mathrm{B}$ and especially $\mathrm{C}$ ). Buildings belonging to category A do not show any strong correlation. However, these buildings do not cover the entire duration span.

Analysis of the use of electricity for building operation has shown a slight tendency for newer buildings having higher use of electricity. This was expected since these systems generally have greater pressure drops over the heat recovery units and other air handling components, which increases the need for electricity for fan operation. On the other hand, these systems typically show a substantially lower use of energy for heating, due to heat recovery from the extract air. Systems equipped with variable air flow (VAV) or demand-control (DCV) will reduce the use of both electricity for fan operation and heat for tempering the supply air, compared to systems with constant airflow rates. There is a possibility however that the ventilation running times and ventilation rates may not be optimised; these factors have been found to significantly influence a school building's energy performance [11]. A very wide range of values for buildings in category A were also found, which shows the great diversity that characterises naturally ventilated buildings.

The focus of the second part of the analysis was on measured indoor air quality indicators and energy performance. Overall, there does not seem to be any strong relationship when considering the entire sample, but this finding changes when the focus shifts again to the ventilation groups. This can be seen in the case of energy performance and operative temperature presented in Figure 5, where a strong negative and significant correlation was observed for mechanically ventilated buildings (groups B and C). One possible explanation for this observation is that it is much easier to maintain stable thermal conditions in buildings having a low use of energy, as these buildings are well insulated and designed to meet energy efficiency criteria. Such buildings are usually either recently built or renovated, and therefore equipped with mechanical systems, which have a predictable, standard operation.

It is of interest to further investigate schools of category A, as the influencing factors of their indoor climate appear to be more complex, most likely with a strong influence from building user behaviour, e.g. regarding the extension of window airing.

No relationship was observed for the case of added humidity indoors. Based on the results it seems that added humidity is almost completely independent from energy efficiency and its value is influenced by other factors.

Even though no strong relationship between energy performance and $\mathrm{CO}_{2}$ concentration was observed, the results have confirmed the important role of the ventilation system in indoor air quality. However, some of the results indicate that even in buildings that are ventilated naturally or with support of exhaust systems (ventilation category A), it is possible to achieve acceptable levels of $\mathrm{CO}_{2}$ concentration. The intermittent nature of natural ventilation through window opening is the most likely cause of the great variance in $\mathrm{CO}_{2}$ levels of category A. The effectiveness of natural ventilation relies on several factors, such as building design, outdoor weather conditions, activity of teachers or building staff responsible for opening the windows, condition of the supportive exhaust systems or additional installation of automated windowopening systems. Another important aspect is the need to maintain certain level of thermal comfort. This can reduce the frequency of window opening under certain seasons or weather conditions and could potentially influence the energy performance, too. This is particularly relevant to cold and 
moderately cold climates, such as those encountered in Sweden.

Natural ventilation is often considered as the least energy efficient way of building ventilation. However, results of this analysis cannot directly support this hypothesis. Even though there seems to be some tendencies shown in Figure 2, additional information is required to better understand this problematic. Based on the results, it seems that older buildings, that are mostly naturally ventilated, tend to have higher energy performance value, but there can be various explanations for this phenomenon, one of them being the fact that many of the old buildings are protected for their historical value and limited number of applicable energy efficiency measures is allowed. Therefore, the higher energy performance value cannot be directly linked only to use of natural ventilation.

Overall, based on this analysis, it seems that mechanically ventilated buildings show clearer tendencies when assessing relationships between energy performance values, building indicators and measured air quality data. For buildings from category $\mathrm{A}$, the relationship is usually weak, and ranges of values are much wider.

\subsection{Limitations of EPC data}

EPC can serve as a valuable tool when analysing building energy performance, however lack of some additional data, such as information about building envelope, renovation processes or main ventilation system in the building makes it difficult to conduct deeper analysis. This information must be obtained from building inspections or by utilizing data from other available databases containing information about the building stock.

Another drawback when using EPCs for analysis of building stock is the frequent changes of legislation resulting in various versions of EPCs that are still valid at the same time. Certificates issued before 2014 miss the energy classification (in a form of assigning the building to an energy class based on the achieved energy performance), and certificates issued after 2019 use primary energy value as the main energy performance indicator. Especially the second mentioned difference makes it more complicated to compare buildings with different versions of EPC without additional adjustments and calculations.

Analysis of energy performance value and construction year revealed further limitations. Year of construction should be used very carefully as an indicator of building performance or state. Information about current state of the building, building envelope or conducted building renovations are some of the information that could help to improve this analysis.

EPC contains only a total value of electricity for building operation and it is not possible to find out what ratio of the total energy is related to each of the systems included in this value (ventilation, elevators etc.). Limitations of using this indicator include the inability to separate only ventilation-related electricity use and that the school buildings can have different layouts resulting in different ratios between classrooms and common areas, which might result in different needs for electricity use in these common areas. It would be especially beneficial to know the use of electricity for the ventilation system, as it would help to deal with this limitation and also to better understand the differences in energy needed for establishing required indoor air quality when using different ventilation systems. It was also found that in many of the investigated schools, this value is not measured separately from other electricity consumption due to the lack of submeters in the system. Therefore, the value stated in EPC might be in some cases only a qualified estimate of the energy experts.

Lastly, energy performance is also significantly influenced by the behaviour of building occupants, difference between system dimensioning and actual use of building, level of building maintenance and current state of building systems. As Swedish EPCs work with purchased energy when calculating final energy performance value, these factors are reflected in the resulting value and can introduce unwanted bias into comparative analysis. On the other hand, EPC working with measured purchased energy provides better picture of the real building operation compared to calculated values.

\section{Conclusion}

This paper presented results from a preliminary analysis of the relationship between IEQ parameters and energy performance in school buildings. The analysis was based on information available from EPCs and in-situ measured IEQ parameters in classrooms of 21 Gothenburg school buildings.

Analysis has demonstrated differences among buildings with different ventilations systems. There seems to be stronger correlations between energy performance and measured IAQ data for mechanically ventilated buildings. For buildings ventilated mostly naturally, the ranges of values are much wider and only weak, or no correlations were observed.

Based on the presented results, it is not possible to derive whether a building with good energy performance has good or poor IAQ. However, some of the relationships point to a need for further analysis of more detailed data and by categories based on building characteristics. The limitations and potential of EPCs as a data tool in such analysis were also discussed.

The analysis shows potential for interesting findings and will be extended in future research with more information and data, allowing for a detailed 
investigation of the relationship between energy performance and IEQ.

We wish to acknowledge the Swedish energy agency Energimyndigheten (project nr. 46866-1) and also the Swedish research council Formas (project nr. 201701015) for financial support of this work. We would also like express our sincere gratitude to Lokalförvaltningen Göteborg, for arranging the access to schools and providing data necessary for this analysis. We would also like to thank to all the teachers, principals and children for their cooperation during the measurement campaign.

\section{References}

[1] P. Wargocki, J. A. Porras-Salazar, S. Contreras-Espinoza, and W. Bahnfleth, "The relationships between classroom air quality and children's performance in school," Building and Environment, vol. 173, p. 106749, 2020/04/15/ 2020, doi: https://doi.org/10.1016/j.buildenv.2020.10 6749.

[2] L. La Fleur, P. Rohdin, and B. Moshfegh, "Energy use and perceived indoor environment in a Swedish multifamily building before and after major renovation," Sustainability (Switzerland), Article vol. 10, no. 3, 2018, Art no. 766, doi: 10.3390/su10030766.

[3] V. Földváry, G. Bekö, S. Langer, K. Arrhenius, and D. Petráš, "Effect of energy renovation on indoor air quality in multifamily residential buildings in Slovakia," Building and Environment, vol. 122, pp. 363-372, 2017/09/01/ 2017, doi: https://doi.org/10.1016/j.buildenv.2017.06 .009 .

[4] DIRECTIVE 2002/91/EC OF THE EUROPEAN PARLIAMENT AND OF THE COUNCIL of 16 December 2002 on the energy performance of buildings, 2002.

[5] C. Hjortling, F. Björk, M. Berg, and T. a. Klintberg, "Energy mapping of existing building stock in Sweden - Analysis of data from Energy Performance Certificates," Energy and Buildings, vol. 153, pp. 341-355, 2017/10/15/ 2017, doi: https://doi.org/10.1016/j.enbuild.2017.06. 073.

[6] K. G. Droutsa, C. A. Balaras, E. G. Dascalaki, S. Kontoyiannidis, and A. A. Argiriou, "Energy Use Intensities for Asset Rating of Hellenic Non-Residential Buildings," Global Journal of Energy Technology Research Updates, vol. 5, no. 1, pp. 19-36, 2018.

[7] M. Gangolells, M. Casals, N. Forcada, M. Macarulla, and E. Cuerva, "Energy mapping of existing building stock in Spain," Journal of Cleaner Production, vol. 112, pp. 3895-3904, 2016/01/20/2016, doi:

https://doi.org/10.1016/j.jclepro.2015.05.1

$\underline{05}$.

[8] J. von Platten, C. Holmberg, M. Mangold, T. Johansson, and K. Mjörnell, "The renewing of Energy Performance Certificates-Reaching comparability between decade-apart energy records," Applied Energy, vol. 255, p. 113902, 2019/12/01/ 2019, doi: https://doi.org/10.1016/j.apenergy.2019.11 3902.

[9] S. Langer, L. Ekberg, D. Teli, B. Cabovska, G. Bekö, and P. Wargocki, "Study of the measured and perceived indoor air quality in Swedish school classrooms," in IOP Conference Series: Earth and Environmental Science, 2020, vol. 588, no. 3: IOP Publishing, p. 032070.

[10] ISO 2017. EN ISO 17772-1:2017 Energy performance of buildings — Indoor environmental quality - Part 1: Indoor environmental input parameters for the design and assessment of energy performance of buildings. Geneva: International Standardisation Organisation.

[11] B. Simanic, B. Nordquist, H. Bagge, and D. Johansson, "Predicted and measured userrelated energy usage in newly built lowenergy schools in Sweden," Journal of Building Engineering, vol. 29, p. 101142, 2020, doi: 10.1016/j.jobe.2019.101142. 